\title{
Penerapan Media Pembelajaran (E-Learning) Sebagai Penunjang Proses Belajar yang Efektif
}

\author{
Karolina Meyer, ${ }^{1}$. Desetina Harefa ${ }^{2}$, Dewi Lidya $\mathrm{S}^{3}$, Christian Rustam Wanggai $^{4}$ \\ Prodi PAK, STT Real Batam \\ Prodi PAK, STT Real Batam \\ Prodi PAK, STT Real Batam \\ Prodi PAK, STT Real Batam \\ karolina39961@gmail.com
}

\begin{abstract}
Learning is a process of change in human personality, and these changes are manifested in the form of an increase in the quality and quantity of behavior such as increased skills, knowledge, attitudes, habits, understanding, skills, thinking power and other abilities. Learning also requires someone who can teach and direct to improve thinking skills and learning skills. The learning process is influenced by two factors, namely: educators and students. In learning, educators are expected to be able to design learning so that it can run according to plan and require electronic media to support the learning process because it is believed to be able to improve skills and can support the learning process to achieve effective learning.
\end{abstract} Keywords: E-Learning, Learning Media, learning outcomes

\begin{abstract}
Abstrak
Belajar adalah suatu proses perubahan dalam kepribadian manusia, dan perubahan tersebut ditampakkan dalam bentuk peningkatan kualitas dan kuantitas tingkah laku seperti peningkatan kecakapan, pengetahuan, sikap, kebiasaan, pemahaman, keterampilan, daya pikir dan lain-lain kemampuan. Belajar juga memerlukan seseorang yang dapat mengajar dan mengarahkan untuk meningkatkan kemampuan berpikir dan keterampilan dalam belajar.

Proses belajar di pengaruhi oleh dua faktor yaitu: pendidik dan peserta didik. Dalam belajar pendidik di harapkan dapat mampu mendesign pembelajaran agar dapat berjalan sesuai perencanaan dan membutuhkan media elektronik sebagai penunjang dalam proses belajar karena di yakini dapat meningkatkan keterampilan serta dapat menunjang proses belajar untuk mencapai pembelajaran yang efektif.

Kata Kunci: E-Learning, Media Pembelajaran, hasil belajar
\end{abstract}

\section{PENDAHULUAN}

Pendidikan merupakan salah satu perwujudan kebudayaan manusia yang dinamis dan penuh dengan perubahan. Karena dengan pendidikan manusia dapat memperoleh pengetahuan, tingkah laku, dan keterampilan. Dan di Era Post modern dengan perkembangan teknologi yang semakin canggih. Manusia di tuntut untuk mengetahui dan memiliki kemampuan dalam mengelolah teknologi. Hal ini juga terjadi dalam proses pembelajaran, yang bertujuan untuk mencapai hasil yang lebih baik, dengan penerapan pembelajaran berbasis media elektronik sebagai penunjang proses belajar, untuk mencapai 
pembelajaran yang efektif dan hal ini dapat meningkatkan kemampuan belajar siswa. Serta dapat menjadi stimulus bagi siswa dalam belajar.

\section{METODE}

Penelitian ini menggunakan metode penelitian Kualitatif deskriptif. Adapun teknik yang digunakan adalah teknik pengumpulan data dari sumber buku untuk mendapatkan informasi dari berbagai macam sumber buku dan pendapat para ahli. Untuk menjelaskan manfaat pembelajaran menggunakan media elektronik (E-learning) sebagai penunjang untuk mencapai pembelajaran yang efektif.

\section{HASIL DAN PEMBAHASAN}

\section{Pengertian Media Pembelajaran}

Menurut terminology, kata media berasal dari bahasa latin "medium" yang artinya perantara, sedangkan dalam bahasa Arab media berasal dari kata "Wasaaila" artinya pengantar pesan dari pengirim kepada penerima pesan.

Gerlach dan Ely mengemukakan bahwa media belajar merupakan alat-alat garis, fotografis atau elektronis untuk menangkap, memproses dan menyusun kembali informasi visual atau verbal ${ }^{1}$

Sedangkan menurut pendapat H. Malik mengemukakan bahwa media belajar adalah segala sesuatu yang dapat digunakan untuk menyalurkan pesan (bahan Pembelajaran), sehingga dapat merangsang perhatian, minat, pikiran dan perasaan pembelajar dalam kegiatan belajar untuk mencapai tujuan pembelajaran tertentu. ${ }^{2}$

\section{Fungsi dan Manfaat Media Pembelajaran}

Istilah media mula-mula di kenal dengan alat peraga, kemudian dikenal dengan istilah audio visual aids (alat bantu pandang/dengar). Selanjutnya disebut instructional materials (materi pembelajaran), dan kini istilah yang lazim digunakan dalam dunia pendidikan nasional adalah instructional media (media pendidikan atau media pembelajaran). Dalam pengembangan, sekarang muncul istilah e-learning . huruf "e" merupakan singkatan dari elektronik. Artinya pembelajaran berupa alat elektronik, meliputi CD Multimedia Interaktif sebagai bahan ajar offline dan website sebagai bahan ajar online.

Pengertian-pengertian diatas sangant mendukung pendapat Soelarko bahwa media pembelajaran memiliki fungsi yaitu memvisualisasikan sesuatu yang tidak dapat dilihat atau sukar dilihat sehingga nampak jelas dan dapat menimbulkan pengertian atau meningkatkan persepsi seseorang. ${ }^{3}$

Media pembelajaran mempunyai kegunaan antara lain:

\footnotetext{
${ }^{1}$ Vernon S Gerlach and Donald P Ely, Teaching and Media: A Systematic Approach (New Jersey: Prentice Hall, 1971).

${ }^{2}$ Oemar H Malik, Media Pendidikan (Bandung: Citra Aditya Bakti, 1994).

${ }^{3}$ R M Soelarko, Audio Visual Media Komunikasi Ilmiah Pendidikan Penerangan, ed. Bina Cipta (Bandung, 1994).
} 
a. Memperjelas pesan agar tidak terlalu verbalitas

b. Mengatasi keterbatasan ruang, waktu, tenaga dan daya indra

c. Menimbulkan gairah belajar, interaksi lebih langsung antara murid dan sumber belajar

d. Memungkinkan anak belajar mandiri sesuai dengan bakat dan kemampuan visual, auditori dan kinestetiknya.

e. Memberi rangsangan yang sama, mempersamakan pengalaman dan menimbulkan persepsi yang sama.

akan tetapi media pembelajaran memiliki 6 fungsi dalam proses belajar dan mengajar antara lain:

a. Penggunaan media belajar dalam proses belajar mengajar bukan merupakan fungsi tambahan, tetapi mempunyai fungsi tersendiri sebagai alat bantu untuk mewujudkan situasi belajar mengajar yang efektif

b. Penggunaan media belajar merupakan bagian yang integral dari keseluruhan situasi mengajar;

c. Media belajar dalam pengajaran penggunaanya integral dengan tujuan dan isi pelajaran

d. Media belajar dalam pengajaran bukan semata-mata alat hiburan atau bukan sekedar pelengkap;

e. Media belajar dalam pengajaran lebih diutamakan untuk mempercepat proses belajar mengajar dan membantu siswa dalam menangkap pengertian yang diberikan guru; dan

f. Penggunaan media belajar dalam pengajaran diutamakan untuk mempertinggi mutu belajar mengajar.

\section{Pengertian E-learning}

E-Learning pertama kali diperkenalkan oleh Universitas IIIlinois di urbanaChampaign menggunkan system instruksi berbasis computer (computer assited instruction) dan computer bernama PLATO. Sejak itu, perkembangan e-learning dari masa ke masa adalah sebagai berikut. ${ }^{4}$ Berdasarkan pengertian e-learning seperti yang dinyatakan Soekarwati, dkk, tersebut. Maka e-learning adalah pembelajaran yang pelaksanaannya didukung oleh jasa elektronis seperti telepon, audio, videotape. Transmisi satelit atau komputer. Berbagai istilah digunakan untuk pendapat tentang pembelajaran elektronik.

E-learning merupakan salah satu pemikiran dalam upaya mengintegrasikan proses pembelajaran dari pembelajaran tradisional, pembelajaran jarak jauh, dan perpaduan berbagai model pembelajaran lainnya.

\section{a. Tradisional e-learning}

Pembelajaran yang umum dan banyak dilakukan dalam lembaga-lembaga pendidikan, di mana proses pembelajaran dan interaksi cenderung banyak melibatkan guru, siswa, media dan sumber belajar buku cetak, serta dukungan peralatan dan sarana standar untuk melayani pembelajaran peserta didiknya.

\footnotetext{
${ }^{4}$ Deni Dermawan, Pengenmbangan E-Learning: Teori Dan Desain (Bandung: Remaja Rosdakarya, 2016).
} 


\section{b. Distance learning}

Pembelajaran jarak jauh awalnya ditujukan guna penyelenggaraan pelatihan atau training dalam jangka waktu pendek. Perkembangannya berlangsung pesat setelah adanya konsep Teknologi Pembelajaran di mana media dan teknologi penyalurnya pesan dalam bentuk komunikasi jarak jauh mampu dilakukan untuk melayani peserta didik.

c. Blended learning

Model pembelajaran Blended learning ini merupakan kombinasi berbagai model pembelajaran yang ditunjukan guna mengoptimalkan proses dan layanan pembelajaran baik jarak jauh, tradisional, bermedia bahkan berbasis komputer.

\section{Penerapan E-Learning Dalam Pembelajaran Sekolah}

Pembelajaran sekolah, baik sekolah dasar maupun sekolah menengah menitik beratkan pada perkembangan kognitif siswa, kreativitas siswa serta koneksi siswa dalam mempelajari berbagai bidang ilmu. Para guru disekolah dasar dan menengah memiliki tugas untuk memastikan para siswanya dapat berkembang secara optimal sesuai dengan karakteristik yang dimiliki oleh siswa itu sendiri. Namun, seiring perkembangan teknologi yang semakin cepat, dunia pendidikan juga secara berjangka melakukan transformasi dalam pendekatan pembelajaran, khususnya pembelajaran sekolah.

Pendekatan human to human masih tetap di gunakan agar interaksi antara siswa dan guru tetap terjalin, namun keberadaan teknologi juga tidak dapat diabaikan, keberadaan teknologi di tengah-tengah transformasi pendidikan menjadikan guru sekolah melakukan inovasi pembelajaran dengan menggunakan teknologi sebagai salah satu alat atau media penghubung. Guru maupun siswa mempelajari dan menemukan kepercayaan diri dalam menggunakan teknologi pada proses pembelajaran didalam kelas

\section{Kelebihan dan kekurangan E-Learning}

Penggunaan E-learning dalam pendidikan memiliki banyak kelebihan bebrapa kelebihan tersebut yaitu :

a. Peserta didik lebih cepat memahami materi ajar karena e-learning memakai multimedia seperti gambar, teks, animasi, suara dan video.

b. Lebih efektif dalam biaya yang berartti peserta didik perlu datang ke gedung belajar dan lebih murah untuk diperbanyak.

c. Lebih efisien karena tidak membutuhkan formalitas kelas, materi ajar bisa langsung di pelajari.

d. Materi ajar bisa dikuasai sesuai dengan kondisi peserta didik seperti semangat dan daya serap peserta didik, bisa di monitor dan bisa di uji dengan e-test. ${ }^{5}$

\footnotetext{
${ }^{5}$ Michael Aristian S et al., "Faktor Yang Mempengaruhi Niat Penggunaan E-Learning Oleh," SENTIKA
} (2016): 18-19. 
Kelebihandengan menggunakan e-learning dalam pembelajaran terlihat dari hasil penelitian yang berjudul penggunaan e-learning dalam pembelajaran Bahasa Indonesia di SMA Negeri Bali Mandara, data mengenai kelebihan e-learning dalam pembelajaran diperoleh dari hasil wawancara dan angket yang diberikan kepada guru mata pelajaran Bahasa Indonesia dan peserta didik kelas XI IPA 1 dan IPA II yang berada di SMA Negeri Bali Mandara. Dari hasil wawancara dan angket tersebut diketahui bahwa $54,54 \%$ peserta didik menyatakan setuju dan 45,45\% sangat setuju bahwa penggunaan e-learning memungkinkan peserta didik untuk belajar sesuai dengan kecepatan belajarnya sendiri berdasarkan minat dan kebutuhan belajar peserta didik.

Sedangkan yang menjadi kekurangan dalam penggunaan e-learning menurut Gavrilova dkk., yaitu dibutuhkan peralatan tambahan untuk menunjang proses pembelajaran seperti computer, monitor, keyboard dan lain sebaginya. ${ }^{6}$ Adapun beberapa kekurangan dari pembelajaran e-learning adalah, sebagai berikut: (1) Interaksi secara tatap muka yang terjadi antara peserta didik dengan pengajar atau antara peserta didik dengan peserta didik lainnya menjadi minim, (2) Pembelajaran yang dilakukan lebih cenderung ke pelatihan bukan pendidikan, (3) Aspek bisnis atau komersial menjadi lebih berkembang dibandingkan aspek sosial dan akademik, (4) Pengajar dituntut lebih menguasai pembelajaran dengan menggunakan ICT, (5) Belum meratanya fasilitas internet yang tersedia di tempat yang bermasalah dengan listrik, telepon dan computer, (6) Sumber daya manusia yang memiliki keahlian untuk mengoperasikan computer masih kurang, (7) Bahasa computer yang belum dikuasai, (8) Perasaan terisolasi dapat terjadi pada peserta didik, (9) Terjadinya variasi kualitas dan akurasi informasi oleh sebab itu di perlukan panduan pada saat menjawab pertanyaan, (10) Kesulitan mengakses grafik, gambar dan video karena peralatan yang dipakai tidak mendukung sehingga menyebabkan peserta didik menjadi frustasi.

\section{Manfaat E-learning Dalam Pembelajaran}

E-learnig mempermudah interaksi antara peserta didik dan materi pelajaran. Demikian juga interaksi antara peserta didik dan pendidik/instruktur maupun antara sesama peserta didik dapat saling berbagi informasi atau pendapat mengenai berbagai hal yang menyangkut pelajaran ataupun kebutuhan pengembangan diri peserta didik. Pendidik/instruksi dapat menempatkan bahan-bahan belajar dan tugas-tugas yang harus dikerjakan oleh peserta didik ditempat tertentu di dalam website untuk akses oleh para peserta didik. Sesuai dengan kebutuhan. Menurut Siahaan manfaat e-learnig dilihat dari sudut, yaitu dari sudut peserta didik dan pendidik. ${ }^{7}$

\footnotetext{
${ }^{6}$ Marina Gavrilova et al., "Computational Science and Its Applications," in ICCSA 2006 : 6th International Conference. Glasgow, UK. (Glasgow: Springer Science \& Business Media, 2006).

${ }^{7}$ Sudirman Siahaan, "E-Learning (Pembelajaran Elektronik) Sebagai Salah Satu Alternatif Kegiatan Pembelajaran," Pendidikan dan Kebudayaan 42, no. 9 (2003): 303-321.
} 


\section{Peserta didik}

Dengan kegiatan e-learnig dimungkinkan berkembangnya fleksibilitas belajar yang tinggi. Artinya, peserta didik dapat mengakses bahan-bahan belajar setiap saat dan ulangulang. Peserta didik juga dapat berkomunikasi dengan pendidik setiap saat.

Dengan kondisi yang demikian ini, peserta didik dapat lebih memantapkan penguasaannya terhadap materi pembelajaran. Maka kegiatan e-learning akan memberikan manfaat kepada peserta didik yang:

a. Belajar disekolah-sekolah kecil di daerah-daerah miskin untuk mengikuti mata pelajaran tertentu tidak dapat diberikan oleh sekolahnya.

b. Mengikuti program pendidikan di rumah (home schoolers) untuk mempelajari materi pembelajaran yang tidak dapat diajarkan oleh para orang tuanya, seperti Bahasa asing, dan keterampilan di bidang komputer.

c. Merasa fobia dengan sekolah atau peserta didik yang dirawat di rumah sakit maupun di rumah. Yang putus sekolah tetapi berminat melanjutkan pendidikannya. Maupun peserta didik yang berada di berbagai daerah atau bahkan yang berada di luar negeri; dan

d. Tidak tertampung di sekolah konvensional untuk mendapatkan pendidikan.

\section{Pendidik/instruksi}

Dengan adanya kegiatan e-learning, beberapa manfaat yang diperoleh pendidik/instruksi antara lain adalah bahwa mereka dapat:

a. Lebih mudah melakukan pemutakhiran bahan-bahan belajar menjadi tanggung jawabnya sesuai dengan tuntutan perkembangan keilmuan yang terjadi:

b. Mengembangkan diri atau karena waktu luang yang demikian relative lebih banyak:

c. Mengontrol kegiatan belajar peserta didik. Bahkan pendidik/instruksi juga dapat mengetahui kapan peserta didiknya belajar, topik apa yang dipelajari berapa lama sesuatu topik dipelajari, serta barapa kali topik tertentu dipelajari ulang;

d. Mengecek apakah pesreta didik telah mengerjakan soal-soal latihan setelah mempelajari topik tertentu;

e. Memerikasa jawaban peserta didik dalam memberitahukan hasilnya kepada peserta didik.

Penyelenggaraan kegiatan e-learning. Menempatkan pendidik/instruksi menjadi factor yang sangat menentukan dan keterampilannya memotivasi peserta didik menjadi hal yang krusial. Pendidik/instruksi haruslah bersikap transparan menyampaikan informasi tentang semua aspek kegiatan pembelajaran sehingga peserta didik dapat belajar secara baik untuk mencapai hasil belajar yang baik. ${ }^{8}$ informasi yang dimaksudkan di sini mencakup:

\footnotetext{
${ }^{8}$ Sukidin et al., "Pendidikan Transformatif Dan Tantangan Masa Depan Bangsa," in Seminar Nasional Pendidikan Transformatif Dan Tantangan Masa Depan Bangsa (Jember: UPT Penerbitan Universitas Jember,
} 
1. Alokasi waktu untuk mempelajari materi pembelajaran dan penyelesaian tugas-tugas

2. Keterampilan teknologis yang perlu dimiliki peserta didik untuk memperlancar kegiatan pembelajarannya; dan

3. Fasilitas dan peralatan yang dibutuhkan dalam kegiatan pembelajaran.

\section{KESIMPULAN}

Media elektronik merupakan salah satu penunjang dalam proses belajar yang dilakukan, baik di sekolah maupun di luar sekolah.

Hal ini telah teruji bahwa proses belajar yang efektif bukan hanya memerlukan kreativitas guru dalam mengajar tentang materi yang siapkan untuk di bagikan kepada murid, tetapi belajar juga memerlukan keterampilan dalam bidang teknologi sebagai penunjang proses belajar yang dinamis.Dengan demikian proses pembelajaran akan lebih efektif jika penerapan media pembelajaran berbasis e-learning dapat di terapkan di sekolah-sekolah Indonesia karena dapat meningkatkan kualitas pendidikan di Indonesia.

\section{KEPUSTAKAAN}

Dermawan, Deni. Pengenmbangan E-Learning: Teori Dan Desain. Bandung: Remaja Rosdakarya, 2016.

Gavrilova, Marina, Osvaldo Gervasi, Vipin Kumar, C J Kenneth Tan, David Taniar, Antonio Lagana, Youngsong Mun, and Hyunsheun Choo. "Computational Science and Its Applications." In ICCSA 2006 : 6th International Conference. Glasgow, UK. Glasgow: Springer Science \& Business Media, 2006.

Gerlach, Vernon S, and Donald P Ely. Teaching and Media: A Systematic Approach. New Jersey: Prentice Hall, 1971.

Malik, Oemar H. Media Pendidikan. Bandung: Citra Aditya Bakti, 1994.

S, Michael Aristian, A Djoko Budiyanto, Benyamin L Sinaga, Program Studi, Teknik Informatika, Fakultas Teknologi Industri, Universitas Atma, Jaya Yogyakarta, and Van Raaij. "Faktor Yang Mempengaruhi Niat Penggunaan E-Learning Oleh." SENTIKA (2016): 18-19.

Siahaan, Sudirman. "E-Learning (Pembelajaran Elektronik) Sebagai Salah Satu Alternatif Kegiatan Pembelajaran." Pendidikan dan Kebudayaan 42, no. 9 (2003): 303-321.

Soelarko, R M. Audio Visual Media Komunikasi Ilmiah Pendidikan Penerangan. Edited by Bina Cipta. Bandung, 1994.

Sukidin, Bambang Suyadi, Sri Wahyuni, Joko Widodo, Pudjo Suharso, and Retna Ngesti Sedyati. "Pendidikan Transformatif Dan Tantangan Masa Depan Bangsa." In Seminar Nasional Pendidikan Transformatif Dan Tantangan Masa Depan Bangsa, 79-88. Jember: UPT Penerbitan Universitas Jember, 2015. https://www.pdfdrive.com/pendidikan-transformatif-dan-tantangan-masa-depanbangsa-d58611068.html.

2015), 79-88, https://www.pdfdrive.com/pendidikan-transformatif-dan-tantangan-masa-depan-bangsad58611068.html. 